\title{
Preliminary review of abstracts on a handbook on the future of work and entrepreneurship for the underserved
}

\author{
JoAnn Rolle \\ School of Business \\ Medgar Evers College, City University of New York, USA \\ Jacqueline Kisato \\ Kenyatta University, Nairobi, Kenya \\ Charles Kebaya \\ Machakos University, Kenya
}

\section{Keyword}

Entrepreneurship, future, innovation, technology, underserved, work.

\begin{abstract}
Scholars have declared that underserved communities will face the greatest marginalization due to disruptions in the 21st century. In our previous research engagements, we developed papers and presentations on 'The Future of Work and Entrepreneurship for the Underserved' and we shared data and our concerns for global income disparities and the need for a global perspective in this discourse.

Purpose of Research-In this paper, we present a global snapshot regarding the future of work and entrepreneurship for the underserved and various perspectives from different authors on what these new changes predict for the underserved in the world.

Design/ Methodology: After reviewing literature and determining key themes imperative to this topic, we put up a call for chapters that attracted diverse authors in academia and industry across the world representing different geographical regions including the USA, South America, Asia, and Africa. The abstracts were peer-reviewed and analyzed to identify commonalities and key areas of focus among the underserved communities worldwide.

Results/Findings: The submitted abstracts found aligned with themes in education, technology and innovation, small business development, and diverse labor markets to the future of work and entrepreneurship for the underserved. They also explored other areas such as increasing utilization of labor in the unscaled economy through creativity and the use of emerging innovations and technologies. Additionally, the COVID 19 pandemic phenomenon was highlighted as a challenge that has exacerbated the need to address the future of work and entrepreneurship post-COVID.

Practical Implications and Conclusions: We propose that unity in community and capacity building is vital to create shared prosperity. In this paper, we will share a summary of the chapters which will be included in the forthcoming handbook and perspectives on what the future of work and entrepreneurship will evolve into the new normal. We hope that this analysis will create further dialogue in academia, industry, and policy on how to ensure that the underserved are included in the future of work and entrepreneurship.
\end{abstract}

\section{Introduction}

A recent New York Times article by Thomas L. Friedman titled, "After the Pandemic, a Revolution in Education and Work Awaits", is an eye opener to the growing and widening income inequality and clearly demonstrates the need for a paradigm shift from preparing job seekers to preparing job creators, and advocacy for technology as a transformer of work culture from the bottom of the social pyramid up (Friedman, 2020). Friedman avers

The reason the post-pandemic era will be so destructive, and creative is that never have more people had access to so many cheap tools of innovation, never have more people had access to highpowered, inexpensive computing, never have more people had access to such cheap credit - virtually free money - to invent new products and services, all as so many big health, social, environmental, and economic problems need solving. 
While we believe education is a necessary ingredient for the transformation of the future of work and entrepreneurship, but it is not sufficient. Key aspects to the future of work include the ability to rapidly skill and up-skill global diverse laborforce as proposed by scholars around the world. It is through up-skilling, unlearning, and re-learning that the next set of employees and entrepreneurs will be ready to meet the new dispensation of work and entrepreneurship. Additionally, leveraging on innovative practices and technology in the "Unscaled" economy is essential for the development and growth of micro, small, and medium businesses (Rolle \& Kisato, 2019, Gatewood \& Sylvain, 2009), and inclusivity are vital to reducing the wage gap between the rich and the underserved globally (McKinsey, 2019, UN, 2020).

\section{Literature Review}

Many disruptions to the concept of work and new ways of living globally have been attributed to changes in technology. These disruptions have resulted in the development of different "ages"; from the Stone Age, Agrarian age, Industrial age, and now the technology age of the 21st century. The 4th Industrial Revolution (4IR) is marked by automation, digitization, artificial intelligence, and augmented realities (Rolle \& Kisato, 2019; Taneja \& Maney, 2018; Galindo and Mendez, 2014).

Scholars and pundits alike declare that the workforce in the 4IR will be more agile, diverse, and creative with the focus on producing bespoke products and services for a highly differentiated marketplace. Rolle \& Kisato (2019) further point out the disparity between the rich and the poor will become a growing concern, and entrepreneurship for underserved communities will be salient to various discourses the world over. These discussions in academia, industry, and political spheres led these authors to develop papers and presentations on "The Future of Work and Entrepreneurship of the Underserved and shared data and their concern for global income disparity (Rolle \& Kisato, 2019).

The critical questions, however, remain: will underserved communities participate in the emergent disruptions on the workforce and entrepreneurial practices? What new dynamics are required to ensure that underserved groups are ready for the future of work and entrepreneurship? Are there any case studies or models of successful integration for the underserved in a tech-centric world of work and entrepreneurship?

\section{Purpose of Research}

It has been noted that often, the underserved are not included in discussions on the future of work and entrepreneurship since a lot of these disruptive innovations take place in developed economies, with developing economies always playing catch up. The purpose of this paper is to expand the geographical reach of these discussions by presenting a snapshot of key areas of focus by authors from various regions globally, who are contributing to an edited handbook on the underserved and how the future of work and entrepreneurship will be transformed for this demography.

This paper seeks to answer 3 key research questions based on the responses from the abstracts received for this edited handbook:

What are the key themes in discourses on the future of work and entrepreneurship for the underserved globally?

How is technology and innovation transforming the future of work and entrepreneurship for underserved communities globally?

What recommendations for academia, practitioners and policy makers will these insights provide for the discourse on the future of work and entrepreneurship globally?

\section{Design/ Methodology}

We made a call for abstracts and the authors were encouraged to use multiple approaches such as empirical, mixed, and case study to their research to ensure that the conclusions attained were grounded on the valid and verifiable evidence-based analysis. To further enhance scientific inquiry, the authors were advised to employ procedures and methods that were systematic and scientifically sound. The authors submitted abstracts on various topics that were peer-reviewed to reduce bias and ensure that scientific rigor was achieved in their methodologies. 
To maintain and ensure robustness in thematic areas, we critically reviewed literature and proposed various key perspectives that are relevant, appropriate, and justifiable for the future of work and entrepreneurship globally. Content analysis was employed to summarize the key thematic areas of the abstracts. To increase reliability in the thematic categorization, the abstracts were reviewed independently by three authors, and the themes correlated to increase inter-coder reliability. These abstracts were summarized in main thematic areas and descriptive statistics were used to evaluate the geographical representation and thematic submissions from various authors. In this paper, we present an analysis of the abstracts from various authors who responded to the call for abstracts and propose recommendations for the future of work discourse.

\section{Results/Findings}

The data were analyzed descriptively to determine the geographical representation of authors and the key thematic areas submitted in the call for abstracts. These data are summarized below based on the geographical representation of authors and the key thematic areas for various abstracts that were submitted for the handbook.

\section{Geographical Representation of the Authors}

The call for abstracts was made to a global audience of scholars and authors by the CBER. The data revealed that the majority of the contributors were scholars and industry practitioners from the USA (39.1\%), followed by Africa and South America with 21.7\% each and Asia (17.4\%); where (N=23). Although there was no contribution from Europe, this demographic representation was considered a representative sample of scholars and practitioners representing underserved regions globally. Our contributors wrote from the perspective of countries in the US, Kenya, India, Pakistan, Chile, Philippines, Bangladesh, Japan, Viet Nam, Nigeria, and Mexico.

\section{Key thematic Areas}

To key thematic areas, the data revealed that the majority of the authors presented abstracts inclined to themes in small businesses and entrepreneurship (34.8\%) and what the future of work means for underserved communities in this sector. Concerning the diversity of the labor markets and education, the authors' representation in these themes was $26.1 \%$ and $21.7 \%$ respectively. Abstracts presented on technology and innovation concerning the future of work was represented by $17.4 \%$ of the respondents to the call; where $(\mathrm{N}=23)$. Although the respondents were more inclined to small business, there was a common thread on how each of the various sectors leveraged technology and innovation to enhance performance or outcomes. This finding was aligned with the main theme of the handbook on the future of work and technology.

\section{Discussions and conclusions}

\section{Content Analysis of Thematic Contributions from the Authors}

Various authors have posited that there are key drivers of inclusivity for the underserved in the Future of work and entrepreneurship globally (Rolle \& Kisato, 2019; Gatewood and Sylvain, 2009; UN, 2020). The Handbook, therefore, will be compiled in the following Chapter sub-sections: Section 1Education: Section 2- Technology and Innovation: Section 3- Small Business Development: Section 4Diversity of Labor Market and Section 5- Summary and Recommendations.

\section{Section 1 - Education and the Changing Dynamics for the Underserved}

Technological growth has exponentially increased in the 21st century. As the revolution comes to education and work, how will we prepare from the bottom up? Various authors have proposed new learning models that are imperative to propel this shift (Rolle, Billy, Kisato, Acevedo, and Zarbabal, 2017; Friedman, 2020). Friedman's article in the New York Times, for instance, cites an on-going shift in skills acquisition and what will become an ever-increasing demand to "learn how to learn" - framed as "radical re-skilling" or "just-in-case-learning" (Friedman, 2020). He further posits that we will finally be in the age of what you know matters more than who you know or more importantly for the global poor, where you come from. Additionally, Friedman cites evidence where academics and corporate partners are creating modular learning ecosystems that are independent of traditional educational constraints or boundaries. 
This concept is supported by numerous scholars globally who emphasized experiential learning and bespoke learning models that will cater to a different student and industry needs.

Although this seems to be a new model, there is little evidence that the purpose to explore education for underserved communities globally aligns them with the future of work and entrepreneurship in the 21st century. This gap in literature becomes a rich ground for academic discourse; thus, reinforce the justification for emphasis on education as a key driver in the Handbook.

Our various scholars start the dialogue on education with a challenge to the academy from the prism of community capacity building and digitalization as a change agent for economic development through entrepreneurial education. The chapter continues with a mixed approach to creating the next generation of entrepreneurs. The chapter addresses challenges for families in extreme poverty and posits ideas for innovation in education and economic prosperity. To address the nexus between education and demand for labor, both macro and micro impacts of Chile's declining mining industry on the demand for labor and the need for rapid adaptation of technology and education is postulated to transform the economy.

The authors discuss technologies used to support student learning in the mining and oil refining processes.

The subsequent chapter explores options for creating the next generation of entrepreneurs in Nigeria for industrial and national growth. The cross-sectional study findings indicated that the entrepreneurial mindset in Nigeria is low due to the opportunity cost of working in white-collar jobs in the public sector. Based on this finding, the authors recommend that entrepreneurial teachings must go beyond traditional teachings in the classroom.

Learning, unlearning, and re-learning have been proposed as the new model for future student in the 4IR. The next chapter amplifies continuing education, business ideas, innovation, and economic prosperity for heads of households in Southeast Asia. The author explores the historical trends of selfown startup businesses in rural communities. Issues addressed are the use of technology; skills needed for business; and opportunities for education, training, and financial support to sustain family businesses.

From the various contributions, it is evident that various scholars indeed declare that the current model of education might not serve in the new dispensation, and scholars, industry players, entrepreneurs, and students must engage in this discourse and re-imagine the new learning needs.

\section{Section 2 - Technology \& innovation for the future of work and entrepreneurship}

The 21st century is characterized by technological disruptions and it is foolhardy to discuss this era without appreciating the role of technology and innovation (Rolle and Kisato, 2019; Galindoa and Mendez, 2014; Daugherty and Wilson, 2018; \& Taneja and Maney, 2018). In the abstract submissions for the handbook, various authors present their insights and findings on what technological changes and innovations will portend for the future of work and entrepreneurship for the underserved.

We present two chapters on "Africa and the Disruptive Age: A discourse of work and entrepreneurship in tumultuous times." In the chapter, "Leveraging Technology and Innovation amidst and post Covid-19 Pandemic to the New Normal" in East Africa the authors reinforce the demand and need for computer-aided and related skills. They predict that the rate of technology and innovation change will produce new products and services in the East African region. They also posit that a "New Normal" will require a change in policy frameworks and regulations to sustain new product development and growth.

The chapter reviews contemporary policy frameworks in the East African States that are foundational technology leverages.

The chapter recommends the need to leverage technology and innovation in a COVID-19 pandemic to "New normal."

From a different prism, another group of authors posits that technology is disrupting the creative industries and entrepreneurial ventures in underserved communities in Africa. The authors cite the diversity of culture, language, and ecology that serves to enhance and sustain multiple creative economies. The authors further indicate that while many industries shrunk during COVID-19, creative industries in Africa experienced growth. The chapter cites actual case studies of successful creative 
industries which adapted a paradigm shift in transforming talent to an enterprise. The authors concur with others that the creative industry will be the next phase of economic growth in Africa.

"Emerging trends of Entrepreneurship and work in Asia and Central America," is a case study of a technology start-up, ability to predict consumer market behavior using advanced technologies. The company's backbone is AI Technologies and Machine Intelligence that predict human behaviors and trends. The case study cited is based in Vietnam and demonstrates how technology delivers predictions and analytics to capture market segment growth. The chapter further shows how community and capacity building is executed with entrepreneurial opportunities to the underserved via a kiosk, low capital investment business model strategy.

The final chapter in this section, "Relationally Intelligent, Transcultural Automation and Innovation: A Learning-centric Strategy for Entrepreneurial Excellence in Underserved businesses" addresses income disparities in the US. The authors propose a trust-based relational intelligence model. Place-making, entrepreneurial ecosystem development and innovation district formations are reviewed. The findings will support cultural-specific policy approaches to innovation and establish practices for regional collaboration, technology adoption for skill transformation, and job creation.

\section{Section 3 - Small business development in underserved communities}

Small business and development have long been heralded as the economic engine of most developing economies, however, the underserved communities in Africa, Asia, and the Americas are sometimes overlooked, further exacerbating the wealth gaps (DeGhetto and Kiggundu, 2016; Rolle and Kisato 2019; McKinsey, 2019). In this section, we present a diverse group of topics ranging from the transformation of urban slums to developing rural areas - both leveraging entrepreneurships. The first chapter is on bootstrapping strategies that transform urban slums.

The author cites several multi-year experiences transforming communities by engaging the entrepreneurial spirits of the poor. Successful cases in Argentina, Panama, and Mexico are presented demonstrating innovative methods of leveraging social capital, bootstrapping slum economies into successful neighborhoods.

In the subsequent chapter, "Development of Entrepreneurship: A Case of Rural Lakshmipur," the author states that much of the entrepreneurship activity is located in urban areas, while there is a need for increased investment in rural-based economies such as Bangladesh. The authors use focus groups, surveys, and interviews to analyze rural entrepreneurial potential. The authors contend that there were both demand and supply-side reasons for the lack of entrepreneurial activity.

Bangladesh and youth entrepreneur startups are the topic of the next chapter. The authors discuss the factors that determine a career path of work or entrepreneurship in the context of COVID-19. The authors address the career readiness for youth regarding the challenges of a complex post-pandemic business environment. The authors, however, share observations on how COVID-19 shifts specific youth startup case studies in Bangladesh.

"Implementation of the comprehensive entrepreneurship model for the internationalization of ecoefficient companies," seeks to develop an integrated model of entrepreneurship in a new model of companies.

The body of work reviews and analyzes technology based on entrepreneurship and develops a strategy that adapts to companies with an ecological basis for internationalization.

In "The Role of MSME in India: A Multiple Case Study Approach," the authors study the role of micro small and medium (MSME) in India. The study uses a multiple-case design of five MSME Indian companies. The results indicate that sustainable solutions exist and that the MSMEs are performing well. In conclusion, the authors provide a set of strategies adopted by the five MSMEs.

The former CEO of Solutions Learning shares his experience as a minority entrepreneur in the US. He observes that many minority entrepreneurs are self-funded and notes that access to opportunity rather than access to capital was the missing link in business success. Access to capital becomes an issue only when there is a need or demand to scale. Eventually, the author shares critical insights for entrepreneurs to live by.

There are two chapters on financing in the Handbook, "Financing small businesses in underserved communities efficiently during a crisis: lessons from the cold-19 pandemic in Kenya" and Inclusive 
Capital: Blueprint for US Economic Resurgence. The first refers to underserved communities as the informal sector in the Kenyan economy and posits that it was the worst hit by the COVID-19 pandemic. Both private and public interventions were made to help and support the sector. The study analyzes and documents the effectiveness of the interventions advanced to small businesses in the sector and shows the essence of financial support to small businesses in the advent of future crises. The next chapter explores the role, impact, and potential of underserved businesses in the US economy. The authors cite widening disparities and suggest lessons learned, discuss inclusion in the context of venture financing, make program and policy recommendations.

"Access \& Impact: Combining community-first and digital methods for entrepreneurial education" is a case study of the Citizen Entrepreneur Explorers Program. The program is based in a US community college over three semesters and resulted in increases in student empathy and entrepreneurial selfefficacy. The author examines how the study outcomes have activated diverse populations of students.

\section{Section 4 - Diversity of labor markets: creating inclusivity for the underserved}

As the labor markets grow across the world, there is rising concern on whether diversity and inclusivity are incorporated by organizations globally (Rolle, Kisato, Rock and Winstanley, 2020; Ganesh, Memon, Kaushl and Kumar, 2018; OECD/European Union 2015). This section summarizes various insights from authors whose themes interlace the future of work with diversity in labor markets.

In "Beautypreneurs in India: Agency, Training, and Determinants of Success", the authors cite gender bias as a factor for the lack of female entrepreneurs.

The authors indicate that the beauty and salon sector is forecast for significant growth and over 70,000 women have been recently trained on-line. The study analyzes the micro-entrepreneurial model among women in underserved communities in India and assesses how the training providers leverage technology to offer online training during COVID-19.

"Effect of COVID-19 pandemic on the performance of women-owned micro-enterprises in Kenya," discusses the impact of lockdowns, curfews, and other public sector mandates on the professional and personal lives of women entrepreneurs. The authors argue that policy interventions favored larger ventures leaving small ventures with little support. Resource-based theory and real-options theory are used to explore options available for women-owned ventures. The preliminary findings indicate that the pandemic had a disproportionate impact on women-owned small businesses in Kenya, and indeed across the world.

"Female Immigrant Entrepreneurs: An Engine to the Inclusive Economic Development," reviews literature on self-employment trends of female immigrants. Using the US IPUMS database, the author explores self-employed immigrant women's human and social capital. The chapter addresses the gap in the literature and develops a case for researching female immigrant entrepreneurship.

"Immigrant Labor, Entrepreneurial education and the future workforce in India, Pakistan and Bangladesh," cites the history, demographics, population, and economy of the region. The author cites the decline in rural areas and trends towards rapid urbanization. workplace.

The chapter discusses the challenges of seasonal migrants noting generational exploitation in the

The author mentions that Bangalore's service and tech-based sector attracting skilled and professional talent from across the region. The study further discusses the problems of migrant workers and suggests several solutions.

"A qualitative study on perceptions of African Americans regarding Work from home benefits during COVID-19" discusses the historical difference between White and African Americans' perceptions related to job selection. The chapter attempts to mitigate barriers of social acceptance in the job selection criteria. The authors report the results of qualitative interviews from students in the job market working from home and its effects on the labor market.

"Workforce Diversity: Creating Profit and Employment Opportunities," cites the trend of recruitment of a more diverse workforce. The chapter discusses corporate interest in workplace discrimination laws; willingness to promote diversity as a social good; and recognition that workforce diversity can impact the bottom line. The purpose of the Chapter is to review methods that workplace diversity can positively impact productivity, revenues, and profits. 
In summary, inclusivity and diversity of the workforce are key ingredients in ensuring the future of work and entrepreneurship since each group brings diverse talents and ultimately creates shared prosperity for all.

\section{Section 5- Summary and recommendations}

While we do not choose deliberately to present all the chapters here, we do believe that there is enough of a sample to provide the reader with the grandeur of the handbook. Once we have compiled the complete body of work, we will synthesize and summarize what we believe will be a roadmap of methods, tools, strategies, and resources to support development, launch, and grow entrepreneurial ventures in underserved communities. We will also glean insights from various authors and suggest recommendations for policy and practice for different players in society.

\section{Limitations and directions for research}

We recommend that the future of work and entrepreneurship are developing discourses globally that need synergy from Academia, Industry, policy, and practitioners. We seek to use these diverse insights from different regions in proposing new pathways in the future of work and entrepreneurship especially for the underserved to achieve more inclusive and shared prosperity for all. We envision that the chapters submitted for the handbook will provide insights on the future of work and entrepreneurship for the underserved. They will provide answers to practical questions in the future of work and entrepreneurship as articulated in this paper and will go a long way in informing policy formulation and enhancing inclusivity for the underserved in the 4IR. We hope that we will create more research through these discussions that seek to enhance an inclusive, diverse, and prosperous future for all in the disruptive world of work and entrepreneurship of the future.

\section{References}

Daugherty, P. and Wilson, J. (2018). Human + Machines; Reimagining Work in the Age of A.I.: Boston, Massachusetts. Harvard Business Review Press.

DeGhetto, K., Gray, J. R., and Kiggundu, M. N. (2016). The African Union's Agenda 2063: Aspirations, challenges, and opportunities for management research. Africa Journal of Management, 2(1), 93-116, viewed 20th October 2020, <http://dx.doi.org/10.1080/23322373.2015.1127090>.

Friedman T. L (2020, October 20). After the Pandemic, a Revolution in Education and Work Awaits: New York Times op ed, viewed 12th November 2020,

<https://www.nytimes.com/2020/10/20/opinion/covid-education-work.html>.

Galindoa M. and Mendez MT. (2014) Entrepreneurship, economic growth, and innovation: are feedback effects at work? Journal of Business Research. vol. 67, Issue 55 p 67: 825-289.

Ganesh, U; Memon, V.; Kaushl, A. and Kumar, K. (2018). The Indian Social Enterprise Landscape Innovation for an Inclusive Future viewed 16th October 2020, <https://www.bertelsmannstiftung.de/fileadmin/files/Projekte/7_Deutschland_und_Asien/Study_The_Indian_Social_Enterprise_Lands cape_2018.pdf\#page $=79>$.

Gatewood, Elizabeth J. and Boko, Sylvain. (2009). Globalization: Entrepreneurial Challenges and Opportunities in the Developing World. Expert Report No. 34 to Sweden's Globalization Council. Stockholm, Sweden. Zoltan et al. (eds.). The role of SMEs and Entrepreneurship in a Globalized economy: Stockholm, Sweden. Expert report no. 34 to Sweden's globalization Council.

McKinsey (2019) The Economic Impact of Closing the Racial Wealth Gap: McKinsey \& Company, viewed 16th October 2020, <https://www.mckinsey.com/industries/public-and-social-sector/our-insights/the-economicimpact-of-closing-the-racial-wealth-gap $>$.

OECD/European Union (2015). The Missing Entrepreneurs 2015: Policies for Self-employment and Entrepreneurship: OECD Publishing. Paris, viewed 14th October 2020,

< https://www.oecd-ilibrary.org/sites/74f22f51- en/index.html?itemId=/content/component/74f22f51-en >.

RolleJ.D, Billy I., Kisato J., Acevedo R., and Zarbabal K. (2017) "The Cultural Genogram: Experiential Entrepreneurship through a Global lens.": New York, USA. Presented at the 6th International Conference on Business \& Economic Development (ICBED), 10-11th April 2017.

Rolle J. D \& Kisato J. (2019). The future of work and entrepreneurship for the underserved. Conference proceedings of the Academy of Business and Retail Management (ABRM), USA. The Business and Management Review, Volume 10 Number 2. 
Rolle J.D, Kisato J. Rock P. \& Winstanley J. (2020) Inclusive Entrepreneurship: A critical look at inclusion of persons with disabilities: USA. The Business and Management Review, Volume 11 Number 1.

Taneja Hemant and Maney Kevin (2018), Unscaled: How AI and a New Generation of Upstarts Are Creating the Economy of the Future: New York. Public Affairs Publishers.

United Nations World Social Report (2020). Inequality in a Rapidly Changing World: United Nations. United Nations publication, viewed 16th October 2020,

<https:// www.un.org/development/desa/dspd/wp-content/uploads/sites/22/2020/01/World-Social-Report2020-FullReport.pdf>. 